\title{
Inverse But Independent Trends in Obesity and Fitness Levels among Greek Children: A Time-Series Analysis from 1997 to 2007
}

\author{
Konstantinos D. Tambalis ${ }^{a}$ Demosthenes B. Panagiotakos ${ }^{a} \quad$ Glykeria Psarra $^{a}$ \\ Labros S. Sidossis ${ }^{a, b}$ \\ ${ }^{a}$ Department of Nutrition and Dietetics, Harokopio University, Athens, Greece \\ ${ }^{\mathrm{b}}$ Department of Internal Medicine-Geriatrics, Sealy Center on Aging, Institute for Translational Sciences and Shriners Burns Institute, \\ University of Texas Medical Branch at Galveston, Galveston TX, USA
}

\section{Keywords}

Childhood obesity · Epidemiology · Exercise

\section{Summary}

Objective: We examined secular trends in physical fitness and BMI status in 8- to 9-year-old Greek children during an 11-year period (1997-2007). Methods: Population data derived from a yearly health survey performed in over $85 \%$ of Greek schools. Anthropometric measurements and physical fitness tests from 651,582 children were analyzed. The gender- and age-specific BMI cut-off points by the International Obesity Task Force were used to define overweight/obesity. Results: Aerobic performance decreased by $4.9 \%$ ( $p<0.001$ ) for boys and $4.4 \%$ ( $p<0.001$ ) for girls between 1997 and 2007 while obesity increased by approximately $50 \%$ in both genders ( $p<$ 0.001). Time-series analyses revealed that the increasing trends in obesity were independent of the reduction in fitness levels. An increase from $21 \%$ in 1997 to $48.2 \%$ in 2007 was observed in the prevalence of the low quartile of aerobic performance for girls $(p<0.001)$ and from $25.7 \%$ in 1997 to $38.7 \%$ in 2007 ( $p<0.001$ ) for boys. Approximately $80 \%$ and $85 \%$ of obese boys and girls, respectively, failed to pass the low quartile of all aerobic tests in 2007. Conclusions: Inverse but independent trends in obesity and fitness levels were observed among Greek children during an 11-year period (19972007), a fact that predisposes our children to serious health risks as they grow older.

\section{Introduction}

Childhood obesity has been recognized as an epidemic in most developed countries [1]. In Greece, the prevalence of obesity has increased by approximately $50 \%$ in the last decade, and nowadays over $40 \%$ of children are overweight and obese [2]. These findings raise serious concerns for the health status of Greek children. Childhood obesity has been shown to be directly associated with the development of metabolic syndrome [3] and future cardiovascular disease (CVD) events. The current epidemic of obesity, at least partly, has been attributed to an environment that promotes excessive food intake and discourages physical activity [4].

Adequate fitness level in childhood is likely to carry favorable behavioral and biological effects into later life [5]. Accumulating epidemiologic evidence demonstrate that improvement in physical fitness, mainly aerobic capacity, is related to better health in children [6-11] in a dose response fashion [12]. In a previous study from our institution we found that central and total adiposity are lower in overweight and obese children with high cardiorespiratory fitness [13]. Furthermore, individuals with high aerobic fitness during adolescence may have lower levels of body fatness as adults [14]. Among adults, a meta-analysis showed that the relative risk for CVD was higher among those who were below the 25th percentile of the fitness distribution compared with those in higher percentiles [15]. In order to prevent an early development of CVD risk factors in childhood and to develop preventive strategies, it is important to monitor trends in the relationship between obesity and physical fitness in children.

There is strong evidence that aerobic fitness varies widely among children around the world [16]. Recent studies report

\section{KARGER \\ Fax +497614520714 \\ Information@Karger.de}

www.karger.com
(C) 2011 S. Karger GmbH, Freiburg

$1662-4025 / 11 / 0042-0165 \$ 38.00 / 0$

Accessible online at:

www.karger.com/ofa
Labros S. Sidossis, PhD

Laboratory of Nutrition and Clinical Dietetics

Department of Nutrition and Dietetics, Harokopio University

70 E. Venizelou Street, Athens 17671, Greece

Tel. +30 21095491-54, Fax -41

lsidossis@hua.gr 
Table 1. Number of children that participated in the study by gender and year

\begin{tabular}{|c|c|c|c|c|c|}
\hline \multirow[t]{2}{*}{ Year } & \multicolumn{2}{|l|}{ Boys } & \multicolumn{2}{|l|}{ Girls } & \multirow[t]{2}{*}{ Total (n) } \\
\hline & $\mathrm{n}$ & $\%$ & $\mathrm{n}$ & $\%$ & \\
\hline 1997 & 31,822 & 51.3 & 30,173 & 48.7 & 61,995 \\
\hline 1998 & 31,802 & 51 & 30,566 & 49 & 62,368 \\
\hline 1999 & 30,264 & 51.3 & 28,714 & 48.7 & 58,978 \\
\hline 2000 & 33,501 & 51.8 & 31,110 & 48.5 & 64,611 \\
\hline 2001 & 31,550 & 51 & 30,224 & 49 & 61,774 \\
\hline 2003 & 33,660 & 51.5 & 31,662 & 48.5 & 65,332 \\
\hline 2004 & 33,175 & 50.8 & 32,109 & 49.2 & 65,284 \\
\hline 2005 & 35,234 & 50.5 & 34,083 & 49.5 & 69,817 \\
\hline 2006 & 35,863 & 51.1 & 34,333 & 48.9 & 70,196 \\
\hline 2007 & 36,396 & 51.1 & 34,831 & 48.9 & 71,227 \\
\hline Total & 333,267 & 51.2 & 317,805 & 48.8 & 651,582 \\
\hline
\end{tabular}

an inverse correlation between obesity and aerobic fitness as measured by the $20 \mathrm{~m}$ shuttle run test in children [17, 18]. However, very sparse data, coming from selected geographic areas, are available for the Greek population [19-21]. Therefore, the aim of the present work was to evaluate the trends in physical fitness and obesity levels between 1997 and 2007, in almost all 8- to 9-year-old children in Greece and to examine their potential inter-relationship.

\section{Participants and Methods}

\section{Participants}

Population data derived from 10 consecutive, national school-based health surveys. Specifically, anthropometric and aerobic fitness data as well as information on age and gender were collected yearly during spring time of each year from 1997 to 2007, with the exception of 2002 in almost all Greek schools of primary education ( $85 \%)$; schools that did not participate were from borderland areas with only small numbers of children. Thus, from 1997 to 2007 a total of 651,582, 8- to 9-year-old children (51\% boys, $49 \%$ girls; $>95 \%$ of the total student population) participated in the present study (table 1).

\section{Study Approval}

Ethical approval for the health survey was graded by the Ethical Review Board of the Ministry of Education.

\section{Fitness Tests}

The following four fitness tests were administered by two trained physical education professionals in each school: a) vertical jump to assess lower body explosive power (jumping up as high as possible from a squatting position), b) small ball throw (1 $\mathrm{kg}$ with both hands in a standing position) to assess upper body explosive strength, c) 30-meter sprint ) from a standing start to evaluate the speed of movement (participants were instructed to run at the highest speed possible in a straight line), and d) 'multi-stage 20-meter shuttle run' with 1-min stages to estimate maximal oxygen consumption $\left(\mathrm{VO}_{2 \max }\right)$ using the formulas proposed by Leger et al. [22, 23]. The 20-meter shuttle run consists of measuring the number of laps completed by subjects running up and down between two lines, set 20 meters apart, at an initial speed of $8.5 \mathrm{~km} / \mathrm{h}$ which increases by $0.5 \mathrm{~km} / \mathrm{h}$ every minute, using a pre-recorded audio tape. Several shuttle runs make up each stage of the test, and students are instructed to keep pace with the signals for as long as possible. The highest speed $(\mathrm{km} / \mathrm{min})$ attained during the final stage was recorded for each student and subsequently used to estimate aerobic fitness in $\mathrm{ml} \mathrm{O}_{2} / \mathrm{kg} / \mathrm{min}$. The validity and reliability of the test to predict $\mathrm{VO}_{2 \max }$ in children and adolescents have been previously reported [23-25]. The aforementioned, widely used fitness tests were selected as being representative of explosive, anaerobic and aerobic performance. Repeat tests ( 2 trials) were allowed for 30-meter sprint, vertical jump and ball throws, and the best performance was recorded.

\section{Anthropometric Measurements}

Children's height and weight were measured in the morning without shoes using a standardized procedure. Weight was measured with electronic scales with a precision of $100 \mathrm{~g}$. Standing height was determined to the nearest $0.5 \mathrm{~cm}$ with the child's weight being equally distributed on the two feet, head back and buttock on the vertical land of the height gauge. BMI was calculated as the ratio of body weight to the square of height $\left(\mathrm{kg} / \mathrm{m}^{2}\right)$. As the most proper for epidemiologic studies, age- and genderspecific BMI cut-off points (according to International Obesity Taskforce (IOTF)) were used for underweight, normal-weight [26], overweight and obese [27] participants.

\section{Data Analysis}

Descriptive information on anthropometric measurements (i.e. height, weight) and fitness tests performances are presented as mean \pm standard deviation (SD). We determined the age- and gender-specific BMI categories of the participants (i.e. underweight, normal weight, overweight and obese) according to the cut-off points proposed by the IOTF [26, 27]. In the current study 'underweight' includes children in all three grades of thinness (i.e. grades 1, 2 and 3). We stratified the results of each fitness test performance in quartiles separately for boys and girls and according to the reference values of quartiles in 1997. Thus, children were classified according to their fitness score of the 1997 in the following categories: lower or poor (1st quartile), middle or good (2nd-3rd quartiles) and upper or excellent (4th quartile). This approach allowed for comparison of children's fitness level between 1997 and 2007 by the use of the same fitness tests. Children in the 4th quartile of the 30-meter sprint and the in first quartile of the remaining three tests were classified as having poor performance. To evaluate the relationships between BMI and fitness tests, the percentage of children in each quartile was calculated among different BMI groups. Comparisons of the categorical variables (i.e. gender, BMI categories and quartiles of performances) were performed using Pearson's chi-square test. To test for differences on fitness levels between 1997 and 2007, the t-test for normally distributed and the Mann-Whitney test for skewed variables were used. Normality was graphically assessed through P-P plots. Tests for monotonous trends by group of gender were performed using time series analysis having the prevalence rate or mean values of $\mathrm{VO}_{2 \max }$ or low quartile of $\mathrm{VO}_{2 \max }$ as the dependent outcome and the year of examination as the independent factor (with lag 0). Serial dependency was evaluated using the partial autocorrelation function; no autocorrelation was observed for various lags. Furthermore, we applied linear mixed models with fixed effects to investigate whether the time series of overweight and obesity is associated with aerobic fitness levels of the participants during the investigated period. Results are presented as bcoefficients \pm SE. The interaction term between gender and fitness on the investigated outcomes was also evaluated. Finally, logistic regression analysis was used to evaluate the association of BMI categories on the likelihood of recording a poor performance in fitness tests. Results are presented as odds ratios (OR) and 95\% confidence intervals (95\% CI). Hosmer-Lemeshow statistic evaluated the goodness-of-fit of the estimated models. Statistical significance level for two-sided hypotheses was set at 0.05 . All statistical analyses were performed using the SPSS version 18.0 software for Windows (SPSS Inc., Chicago, IL, USA). 


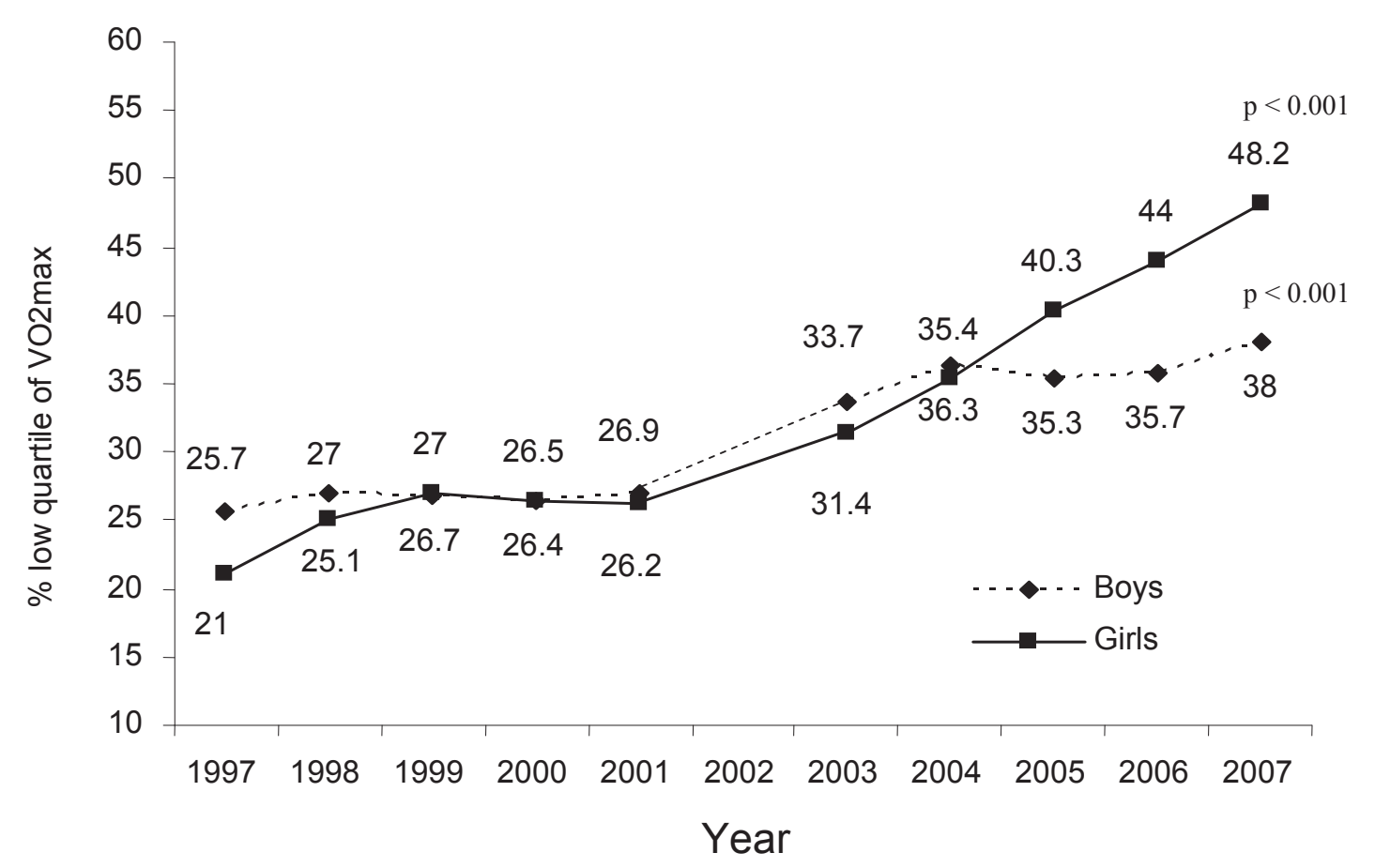

Fig. 1. Secular trends (1997-2007) of the prevalence of children belonging to low quartile of aerobic performance (upper plot) and the prevalence of obesity (lower plot). $P$ value for trend derived from timeseries analysis.

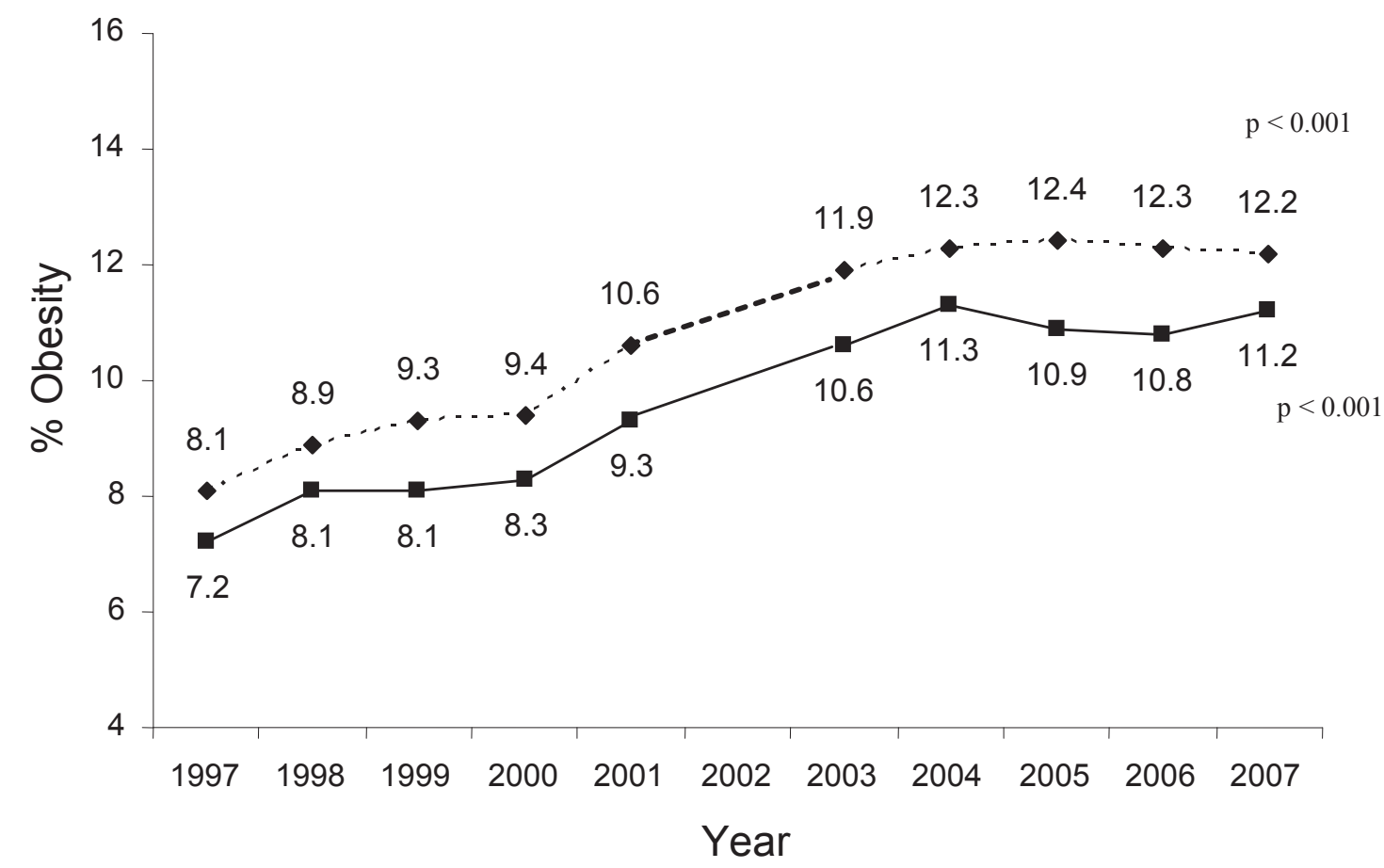

\section{Results}

Secular Trends in Fitness Levels

The level of aerobic fitness decreased by $4.9 \%(\mathrm{p}<0.001)$ for boys and 4.4\% ( $<$ < 0.001) for girls between 1997 and 2007. Specifically, the annual rate of decrease for $\mathrm{VO}_{2 \max }$ was -0.24 $\pm 0.01 \mathrm{ml} \mathrm{O} / \mathrm{kg} / \mathrm{min} /$ year in boys $(\mathrm{p}<0.001)$ and $-0.20 \pm 0.01$ $\mathrm{ml} \mathrm{O}_{2} / \mathrm{kg} / \mathrm{min} /$ year in girls $(\mathrm{p}<0.001)$. The percentage of boys in the lowest quartile of aerobic performance increased from $25.7 \%$ in 1997 to $38 \%$ in 2007 ( $\mathrm{p}<0.001$ ), with an annual trend equal to $1.16 \pm 0.23 \%(\mathrm{p}<0.001)$. In girls this percentage increased from $21 \%$ in 1997 to $48.2 \%$ in 2007 ( $<<0.001$ ), with an annual trend equal to $2.35 \pm 0.32 \%$ ( $\mathrm{p}<0.001)$ (fig. 1 , upper plot). The overall annual trend was higher (almost doubled) in girls as compared with boys $(p=0.06)$. Stratified analysis by BMI category (fig. 2) revealed that the annual increase in the percentage of boys classified in the lowest quartile of aerobic performance was: $1.13 \pm 0.29 \%(p=0.005)$ for underweight, $0.99 \pm 0.22 \%(\mathrm{p}=0.002)$ for normal-weight, $0.88 \pm 0.31 \%(p=0.022)$ for overweight and $0.72 \pm 0.29 \%$ 


\section{Girls}

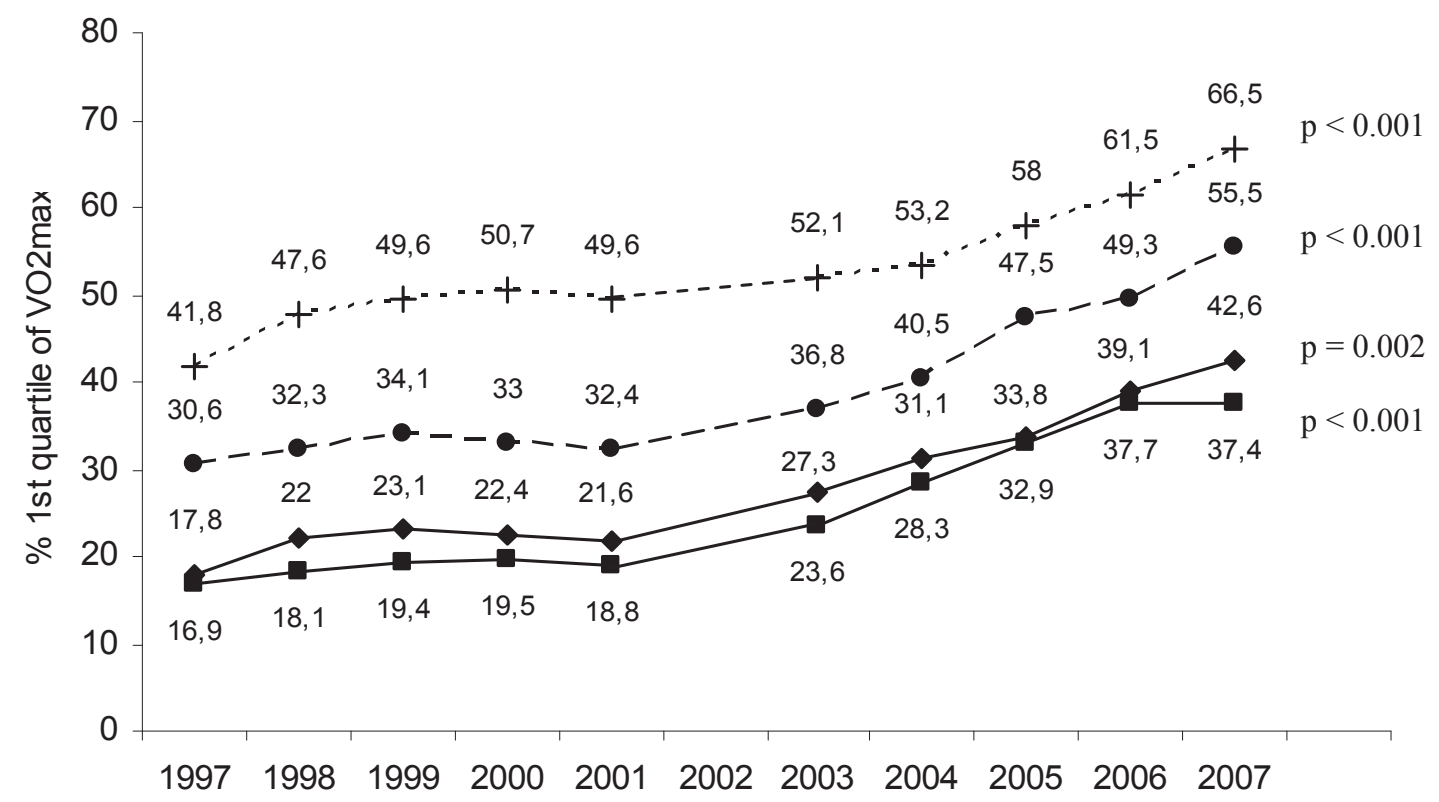

Fig. 2. Secular trends (1997-2007) of the prevalence of children belonging to low quartile of aerobic performance by weight status in girls (upper plot) and boys (lower plot). P value for trend derived from time-series analysis.

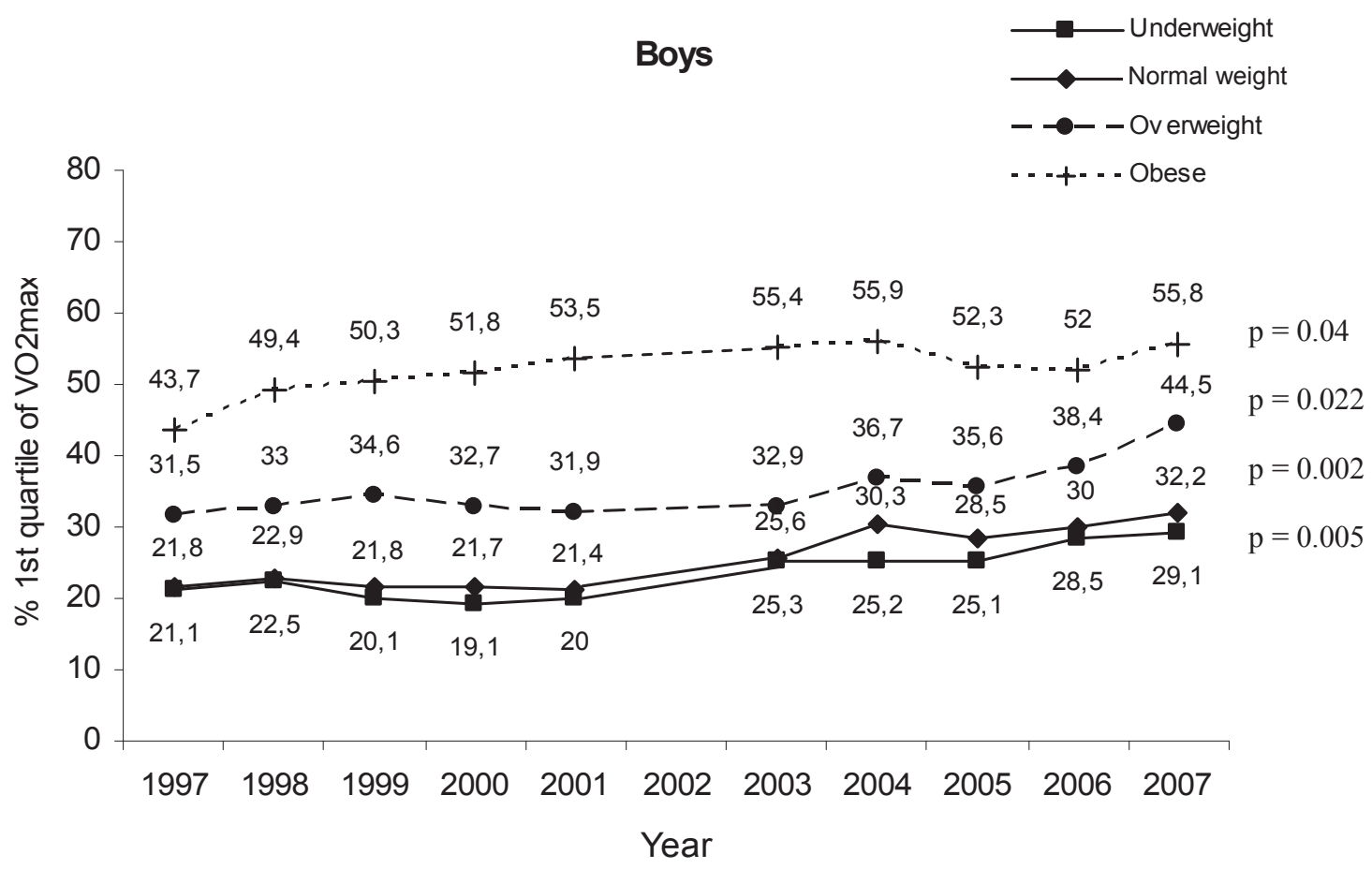

( $\mathrm{p}=0.04)$ for obese boys. Similarly, in girls, the corresponding annual increase was: $2.04 \pm 0.34 \%(\mathrm{p}<0.001)$ for underweight, $2.14 \pm 0.31 \%(\mathrm{p}<0.001)$ for normal-weight, $2.10 \pm 0.47 \%(p=0.002)$ for overweight and $1.99 \pm 0.30 \%$ $(p<0.001)$ for obese girls. The independent effect of gender on fitness levels was analyzed separately in underweight, normal-weight, overweight and obese children. Except for overweight children where boys had a significantly lower rate of low aerobic fitness as compared with girls $(4.0 \pm 1.7 \%$; $\mathrm{p}=0.03)$, gender differences were not observed, neither in underweight $(\mathrm{p}=0.28)$ nor in normal-weight $(\mathrm{p}=0.09)$ nor in obese children $(\mathrm{p}=0.48)$.

The distribution of boys and girls by quartile of aerobic fitness and category of body weight is presented in table 2 . Between 1997 and 2007, the percentage of boys and girls with excellent aerobic performance (i.e. 4th quartile) decreased within all BMI categories (all $\mathrm{p}<0.05$ ), while poor performance (i.e. 1st quartile) showed a substantial increase (all $\mathrm{p}<0.05$ ). Furthermore, the higher the percentage of children in the lowest quartile of aerobic fitness the higher 
Table 2. Performance changes between 1997 and 2007 in quartile ranks of physical fitness testsaccording to $\mathrm{BMI}^{\mathrm{a}}$

\begin{tabular}{|c|c|c|c|c|c|c|}
\hline & \multicolumn{3}{|c|}{ \% Boys } & \multicolumn{3}{|c|}{$\%$ Girls } \\
\hline & poor & good & excellent & poor & good & excellent \\
\hline \multicolumn{7}{|l|}{1997} \\
\hline \multicolumn{7}{|l|}{ Shuttle run } \\
\hline Underweight & 21.1 & 39.1 & 39.8 & 16.9 & 43.5 & 39.6 \\
\hline Normal weight & $21.8^{*}$ & 41.9 & $36.3^{*}$ & $17.8^{*}$ & 46.4 & $35.8^{*}$ \\
\hline Overweight & 31.5 & 47.5 & 21.0 & 30.6 & 48.0 & 21.4 \\
\hline Obese & 43.7 & 46.0 & 10.3 & 41.8 & 45.6 & 12.6 \\
\hline \multicolumn{7}{|l|}{ Sprint $30 \mathrm{~m}$} \\
\hline Underweight & 20.4 & 53.2 & 26.4 & 21.7 & 49.2 & 29.1 \\
\hline Normal weight & $20.0^{*}$ & $51.0^{\S}$ & $29.0^{*}$ & $20.8^{*}$ & $50.6^{\S}$ & $28.6^{*}$ \\
\hline Overweight & 34.0 & 49.5 & 16.5 & 30.9 & 52.0 & 18.1 \\
\hline Obese & 50.4 & 42.1 & 7.5 & 47.3 & 41.7 & 11.0 \\
\hline \multicolumn{7}{|l|}{ Vertical jump } \\
\hline Underweight & 27.3 & 35.8 & 36.9 & 18.1 & 43.2 & 38.7 \\
\hline Normal weight & $27.7^{*}$ & 34.4 & $37.9^{*}$ & $18.7^{*}$ & 42.5 & $38.8^{*}$ \\
\hline Overweight & 42.3 & 35.1 & 22.6 & 26.5 & 47.3 & 26.2 \\
\hline Obese & 58.3 & 29.9 & 11.8 & 38.2 & 43.4 & 18.4 \\
\hline \multicolumn{7}{|l|}{ Ball throw } \\
\hline Underweight & 35.5 & 50.5 & 14.0 & 37.4 & 48.7 & 13.9 \\
\hline Normal weight & 26.7 & 50.7 & $22.6^{8}$ & 26.6 & 49.6 & $23.8^{\S}$ \\
\hline Overweight & 23.5 & 49.1 & 27.4 & 22.4 & 48.7 & 28.9 \\
\hline Obese & 21.3 & 46.8 & 31.9 & 20.0 & 44.8 & 35.2 \\
\hline \multicolumn{7}{|l|}{2007} \\
\hline \multicolumn{7}{|l|}{ Shuttle run } \\
\hline Underweight & 26.1 & 46.3 & 27.6 & 37.4 & 30.0 & 32.6 \\
\hline Normal weight & $32.1^{*}$ & $46.8^{\S}$ & $21.1^{*}$ & $42.6^{*}$ & 30.1 & $27.3^{*}$ \\
\hline Overweight & 44.5 & 46.0 & 9.5 & 55.6 & 29.5 & 14.9 \\
\hline Obese & 55.8 & 37.1 & 5.1 & 66.5 & 24.8 & 8.7 \\
\hline \multicolumn{7}{|l|}{ Sprint 30 m } \\
\hline Underweight & 15.3 & 45.6 & 39.1 & 16.4 & 43.1 & 37.5 \\
\hline Normal weight & $17.3^{*}$ & 44.3 & $38.5^{*}$ & $16.7^{*}$ & 48.4 & $34.9^{*}$ \\
\hline Overweight & 32.1 & 48.9 & 18.9 & 30.4 & 50.0 & 19.6 \\
\hline Obese & 47.4 & 43.1 & 9.5 & 46.9 & 40.7 & 12.4 \\
\hline \multicolumn{7}{|l|}{ Vertical jump } \\
\hline Underweight & 20.4 & 50.0 & 29.5 & 18.7 & 47.3 & 34.0 \\
\hline Normal weight & $25.2^{*}$ & $47.5^{\S}$ & $27.3^{*}$ & $19.5^{*}$ & 47.2 & $33.3^{*}$ \\
\hline Overweight & 37.6 & 46.0 & 16.4 & 31.1 & 47.5 & 21.4 \\
\hline Obese & 51.6 & 37.9 & 10.4 & 37.6 & 46.3 & 16.1 \\
\hline \multicolumn{7}{|l|}{ Ball throw } \\
\hline Underweight & 39.3 & 41.6 & 19.1 & 33.6 & 45.6 & 20.8 \\
\hline Normal weight & 30.4 & 42.6 & $27.0^{\S}$ & 24.1 & 46.6 & $29.3^{8}$ \\
\hline Overweight & 30.2 & 39.4 & 30.4 & 21.8 & 45.4 & 32.8 \\
\hline Obese & 25.2 & 37.3 & 37.5 & 19.0 & 39.9 & 41.1 \\
\hline
\end{tabular}

${ }^{\mathrm{a}}$ Results are presented as percentages. Poor $=1$ st quartile; $\operatorname{good}=2 \mathrm{nd} / 3 \mathrm{rd}$ quartiles; excellent $=4$ th quartile.

${ }^{*} \mathrm{p}<0.05$ for differences in quartile ranks between normal weight and overweight, obese. ${ }^{8} \mathrm{p}<0.05$ for differences in quartile ranks between normal weight and obese.

P-values derived through the application of chi-square test. the rates of overweight/obesity ( $1 \%$ increase in the percentage of low quartile of aerobic fitness corresponded to an increase of the prevalence of overweight/obesity by $0.72 \pm$ $0.16 \%,(p<0.001)$ in boys and $0.41 \pm 0.04 \%(p=0.002)$ in girls).
Overweight / Obesity Secular Trends and Fitness Levels

Figure 1 (lower plot) illustrates the concurrent increase in the prevalence of obesity throughout the studied period for boys and girls separately. Evaluating the effect of gender on obesity levels, it was observed that boys as compared with girls had 


\section{Boys}

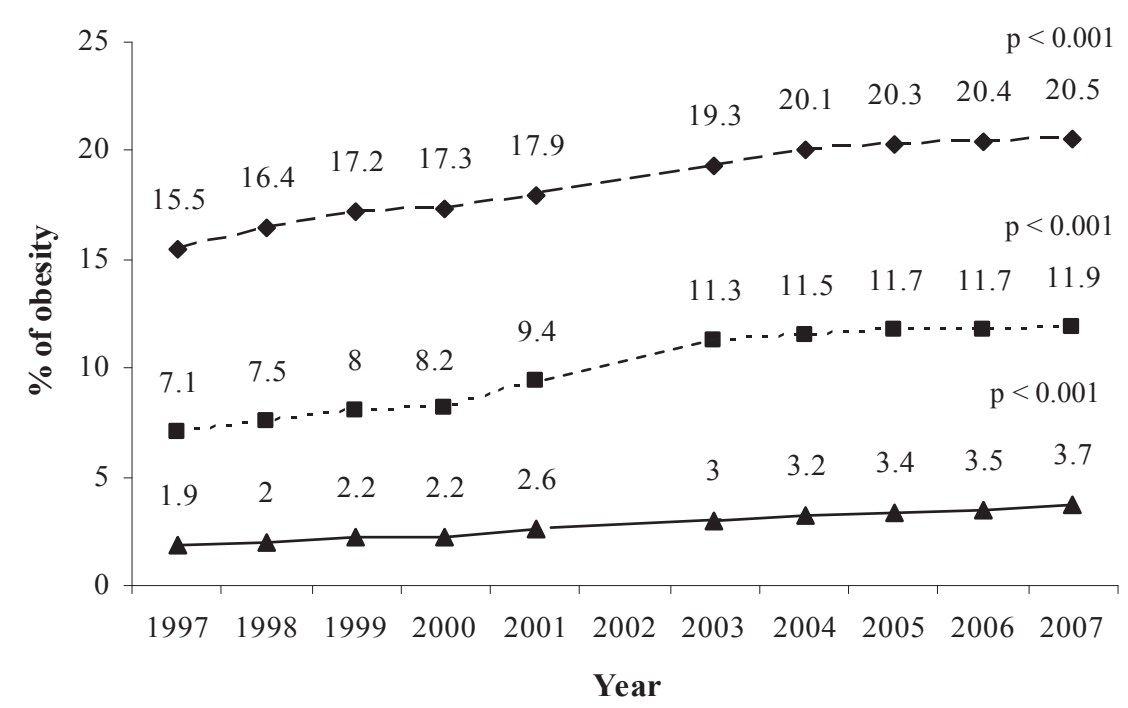

Girls

Fig. 3. Secular trends (1997-2007) of the prevalence of obesity by quartile of aerobic performance in girls (upper plot) and boys (lower plot).

$P$ value for trend derived from timeseries analysis.

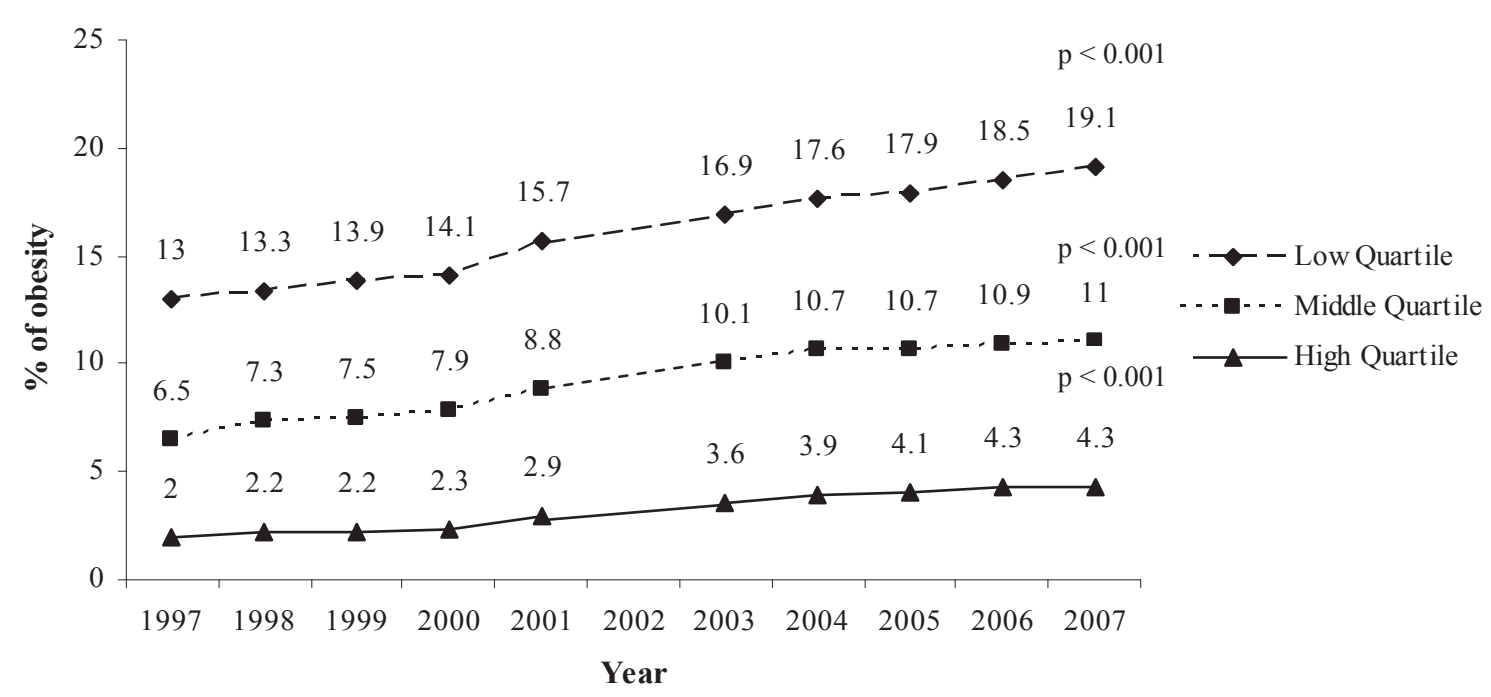

gesting that the reduction in aerobic fitness levels over time cannot fully explain the increase in the prevalence of overweight and obesity in our population.

The mean value for speed between 1997 and 2007 increased by $1.2 \%$ in boys $(\mathrm{p}=0.008)$ and by $2.0 \%$ in girls $(\mathrm{p}=0.001)$. The mean values for upper body (ball throw) and lower body strength (vertical jump) did not change during the study period. The proportions of poor, good and excellent performances for 30-meter sprint, ball throw and vertical jump tests by weight status are presented in table 2. In total, compared with normal-weight children, overweight and obese children showed better performances only in upper body strength test; on the other hand obese children performed worst in all other tests. Taking all four fitness tests together, we calculated an overall fitness index (scale ranging from 0 to 4 according to the number of fitness tests 'succeeded'). Using 
Table 3. Changes between 1997 and 2007 in the prevalence of the number of fitness tests failed to pass 25 th percentile

\begin{tabular}{|c|c|c|c|c|c|c|c|c|}
\hline \multirow{2}{*}{$\begin{array}{l}\text { Number of fitness tests failed } \\
\text { to pass } 25 \text { th percentile* }\end{array}$} & \multicolumn{4}{|l|}{ \% Boys } & \multicolumn{4}{|l|}{ \% Girls } \\
\hline & underweight & $\begin{array}{l}\text { normal } \\
\text { weight }\end{array}$ & overweight & obese & underweight & $\begin{array}{l}\text { normal } \\
\text { weight }\end{array}$ & overweight & obese \\
\hline \multicolumn{9}{|l|}{1997} \\
\hline 0 (fit) & 41.3 & $44.3^{\S}$ & 30.1 & 17.3 & 43.4 & $48.3^{\S}$ & 38.1 & 25.6 \\
\hline 1 & 29.2 & 29.8 & 31.0 & 27.6 & 31.9 & 29.8 & 32.3 & 32.1 \\
\hline 2 & 18.7 & $16.1^{\S}$ & 22.2 & 27.0 & 15.8 & $14.5^{\S}$ & 18.2 & 24.5 \\
\hline 3 & 8.1 & $7.5^{\S}$ & 12.8 & 21.7 & 6.9 & $5.8^{\S}$ & 8.7 & 13.7 \\
\hline 4 & 2.6 & $2.4^{\S}$ & 3.9 & 6.4 & 2.1 & $1.6^{\S}$ & 2.7 & 4.2 \\
\hline \multicolumn{9}{|l|}{2007} \\
\hline 0 (fit) & 41.3 & $41.3^{\S}$ & 30.0 & 20.3 & 37.0 & $37.5^{\S}$ & 25.6 & 16.5 \\
\hline 1 & 34.5 & 34.2 & 31.2 & 29.0 & 34.1 & 35.8 & 34.0 & 33.5 \\
\hline 2 & 16.5 & $15.9^{\S}$ & 20.8 & 27.0 & 19.8 & $17.9^{\S}$ & 23.7 & 27.8 \\
\hline 3 & 6.1 & $6.3^{\S}$ & 11.8 & 16.7 & 7.2 & $6.6^{\S}$ & 12.5 & 16.6 \\
\hline 4 & 1.6 & $2.3^{\S}$ & 6.1 & 7.0 & 1.9 & $2.2^{\S}$ & 4.3 & 5.6 \\
\hline
\end{tabular}

${ }^{\mathrm{a}}$ Results are presented as percentages.

*25th percentile: the low quartile in any of the four fitness tests.

${ }^{\S} \mathrm{p}<0.05$ for differences in the proportions of children failed to pass $0,1,2,3$ or 4 fitness tests, between normal weight and overweight, obese.

$\mathrm{P}$ values derived through the application the chi-square test.

this index, we classified children according to the number of the four physical fitness tests that failed to pass the low quartile (table 3). Approximately $80 \%$ and $85 \%$ of obese boys and girls, respectively, failed to pass the low quartile in all tests in 2007. Moreover, in 2007 the proportion of fit girls in all BMI groups was significantly lower in comparison to 1997 ( $\mathrm{p}<0.001)$. Overall, the crude coefficients (b-coefficient \pm $\mathrm{SE}$ ) between the combined fitness index and BMI were $0.45 \pm 0.01$ in $1997(\mathrm{p}<0.0001)$ and $0.65 \pm 0.01$ in 2007 ( $\mathrm{p}<0.0001)$. A highly significant interaction between combined index and gender on BMI levels in 1997 ( $\mathrm{p}<0.0001$ ) was observed, whereas a borderline interaction was found in 2007 $(p=0.092)$. Thus, further gender-specific analysis showed that there was a gender difference in the crude effects of fitness on BMI levels in $1997(0.51 \pm 0.01, \mathrm{p}<0.0001$ for boys and $0.38 \pm 0.02, \mathrm{p}<0.0001$ for girls; $\mathrm{p}$ for gender differences $<$ $0.001)$, but not in $2007(0.67 \pm 0.02, \mathrm{p}<0.0001$ for boys and $0.62 \pm 0.02, p<0.0001$ for girls, $p$ for gender differences $=0.06$ )

The results of poor performance in each physical fitness test according to BMI category are presented in table 4 . The likelihood of low performance was higher for overweight and obese children in all tests, except for ball throw. In contrast, underweight children were less probable to present poor performances compared with their normal-weight counterparts (except for ball throw).

\section{Discussion}

Our data confirm the hypothesis that overweight and obese children have lower performances in all fitness tests exam- ined, with the exception of the upper body strength test. It is noteworthy, albeit disturbing, to note that between 1997 and 2007, the percentage of 8- to 9-year-old Greek boys and girls with low aerobic fitness increased significantly, irrespective of BMI status.

The present study shows a significant decrease in aerobic fitness for both genders with a mean yearly rate of about $0.40 \%$. Our results are in line with two recently published reviews [16, 28], reporting a rapid secular decline in 20-meter shuttle run performance in children and adolescents over the last 20 years (mean yearly decline of $0.44 \%$ and $0.40 \%$ for boys and girls respectively). Low fitness is an independent predictor of all-cause and CVD mortality - after adjustment for other mortality predictors including body mass [29]. In children, low fitness has been associated with risk factors such as hyperlipidemia, hypertension and obesity $[6,30]$. Andersen et al. [12] examining the association between aerobic fitness and the clustering of CVD risk factors in children, showed that the OR for clustering in each quartile of fitness, using the quartile with the highest fitness score as reference, were 13.0, 4.8 or 2.5 , independently of country, age and sex. On the other hand, it has been suggested that being fit, per se, may reduce the risk of obesity in children $[13,17]$. With regard to the low aerobic fitness level in Greek children [21] it is imperative to design programs aiming at improving aerobic fitness levels in children.

Our study suggests that overweight and obesity are indicative of poor performances in aerobic and motor fitness, with the exception of upper body strength, in both sexes (tables 2, 4). These findings are in agreement with studies by Mamalakis et al. [20], Koutedakis et al. [19] and Tokmakidis et al. [21] 
Table 4. Association between BMI categories on poor physical fitness tests performances (dependent outcome), in Greek 8- to 9-year-old children

\begin{tabular}{|c|c|c|c|c|c|c|c|c|}
\hline & \multicolumn{8}{|c|}{ Poor physical fitness test performance* } \\
\hline & \multicolumn{2}{|l|}{ shuttle run $20 \mathrm{~m}$} & \multicolumn{2}{|l|}{ sprint $30 \mathrm{~m}$} & \multicolumn{2}{|l|}{ vertical jump } & \multicolumn{2}{|c|}{ upper body strength } \\
\hline & OR (95\% CI) & & OR (95\% CI) & $\mathrm{p}$ value & OR (95\% CI) & $\mathrm{p}$ value & OR (95\% CI) & $\mathrm{p}$ value \\
\hline \multicolumn{9}{|l|}{1997} \\
\hline \multicolumn{9}{|l|}{ Boys } \\
\hline Underweight & $0.96(0.86-1.07)$ & 0.477 & $1.02(0.92-1.14)$ & 0.472 & $0.98(0.89-1.07)$ & 0.670 & $1.51(1.38-1.66)$ & $<0.001$ \\
\hline Normal weight & 1.00 & reference & 1.00 & reference & 1.00 & reference & 1.00 & reference \\
\hline Overweight & $1.65(1.54-1.76)$ & $<0.001$ & $2.06(1.93-2.19)$ & $<0.001$ & $1.92(1.80-2.04)$ & $<0.001$ & $0.84(0.79-0.90)$ & $<0.001$ \\
\hline Obese & $2.78(2.55-3.03)$ & $<0.001$ & $4.06(3.72-4.42)$ & $<0.001$ & $3.65(3.36-3.98)$ & $<0.001$ & $0.74(0.67-0.82)$ & $<0.001$ \\
\hline \multicolumn{9}{|l|}{ Girls } \\
\hline Underweight & $0.94(0.84-1.04)$ & 0.249 & $1.08(0.99-1.18)$ & 0.078 & $0.96(0.87-1.06)$ & 0.437 & $1.65(1.52-1.78)$ & $<0.001$ \\
\hline Normal weight & 1.00 & reference & 1.00 & reference & 1.00 & reference & 1.00 & reference \\
\hline Overweight & $1.67(1.56-1.79)$ & $<0.001$ & $1.72(1.61-1.83)$ & $<0.001$ & $1.57(1.47-1.68)$ & $<0.001$ & $0.79(0.74-0.85)$ & $<0.001$ \\
\hline Obese & $2.69(2.44-2.96)$ & $<0.001$ & $3.17(2.89-3.47)$ & $<0.001$ & $2.69(2.44-2.96)$ & $<0.001$ & $0.69(0.62-0.77)$ & $<0.001$ \\
\hline \multicolumn{9}{|l|}{2007} \\
\hline \multicolumn{9}{|l|}{ Boys } \\
\hline Underweight & $0.87(0.79-0.95)$ & 0.002 & $0.78(0.69-0.88)$ & $<0.001$ & $0.86(0.78-0.95)$ & 0.003 & $1.48(1.36-1.62)$ & $<0.001$ \\
\hline Normal weight & 1.00 & reference & 1.00 & reference & 1.00 & reference & 1.00 & reference \\
\hline Overweight & $1.69(1.60-1.78)$ & $<0.001$ & $2.33(2.19-2.47)$ & $<0.001$ & $1.79(1.69-1.89)$ & $<0.001$ & $0.99(0.94-1.05)$ & 0.721 \\
\hline Obese & $2.67(2.48-2.85)$ & $<0.001$ & $4.29(3.98-4.62)$ & $<0.001$ & $2.49(2.32-2.67)$ & $<0.001$ & $0.77(0.17-0.83)$ & $<0.001$ \\
\hline \multicolumn{9}{|l|}{ Girls } \\
\hline Underweight & $0.80(0.74-0.87)$ & $<0.001$ & $0.99(0.90-1.11)$ & 0.96 & $0.95(0.86-1.05)$ & 0.337 & $1.59(1.47-1.73)$ & $<0.001$ \\
\hline Normal weight & 1.00 & reference & 1.00() & reference & 1.00 & reference & 1.00 & reference \\
\hline Overweight & 1.68 (1.59-1.77) & $<0.001$ & $2.08(1.95-2.21)$ & $<0.001$ & 1.87 (1.76-1.99) & $<0.001$ & $0.93(0.88-0.99)$ & $<0.024$ \\
\hline Obese & $2.67(2.47-2.88)$ & $<0.001$ & $3.46(3.20-3.74)$ & $<0.001$ & $2.49(2.30-2.69)$ & $<0.001$ & $0.74(0.67-0.81)$ & $<0.001$ \\
\hline
\end{tabular}

$*$ Test scores lower than the 25 th percentile. Results derived through the application of logistic regression analysis.

OR $=$ Odds ratio; $95 \% \mathrm{CI}=95 \%$ confidence interval.

from selected regions of Greece, reporting that aerobic fitness was inversely related with obesity in children and adolescents. Moreover, our findings are in line with those from recent studies in children and adolescents, e.g. Stigman et al. [17], Stratton et al. [18], Westerstahl et al. [31] and Huotari et al. [32], reporting that aerobic fitness and obesity rates follow opposite trends. Most of these studies have used the 20-meter shuttle run and IOTF cut-off points; therefore, their data are directly comparable to ours.

One would expect a relationship between the rise in obesity and the concurrent decline in aerobic fitness of Greek children over the past 11 years. However, time series analyses revealed that the increasing trends in the prevalence of overweight and obesity in Greek children were independent of the reduction in fitness levels in this population. Aerobic fitness depends on both nonmodifiable (i.e. genetics, maturation) and modifiable (i.e. physical activity levels) factors [33, 34]. On the other hand, an increase in fatness may be due to increased energy intake, decreased energy expenditure or a combination of both. Apparently, apart from physical fitness, other factors (e.g. energy intake, genetic predisposition to obesity etc.) seem to play an important role in the regulation of body weight in young children.
In the present study we observed a small improvement for speed $(0.02-0.03 \% /$ year $)$ and no significant changes for strength over the last 11 years. These findings are in agreement with data from previous studies, suggesting that there is a relative stability in anaerobic fitness test performances in the last decade, with a small annual improvement of $0.03 \%$ and $0.04 \%$ for power and speed, respectively [35]. In children information in children on the relationship between performance in anaerobic tests and weight status is limited [21, 36-38]. Moreover, the variety of fitness tests used makes the comparison between studies difficult. Our results confirm the notion that not only aerobic fitness but also other components of physical fitness such us speed and lower body explosive power are negatively related with obesity in cross-sectional analyses. In a study by Bovet et al., 2007 [36], using similar tests to those used in the present study for assessing body strength (ball throw, vertical jump) and speed (30-meter sprint), results are similar. Specifically, the authors reported that overweight and obese students performed better in ball throw than their normal-weight and lean counterparts while in vertical jump and 30-meter sprint BMI category is inversely to the performance. The earlier finding is probable due to the fact that the specific test requires mainly strength and is insensi- 
tive to body weight.Although the excess body weight of overweight/obese children can affect their performance, obese children may be less keen to participate in moderate or vigorous intensity physical activities because of fear of poor performance and stigmatization by their counterparts. In other words, low participation in physical activities may lead to a vicious circle of perpetuation of obesity. On the other hand, even small increases in physical activity could significantly improve insulin sensitivity and delay or abolish the onset of the metabolic syndrome, even in the absence of any changes in body weight [39]. From the public health care perspective, we must focus on all 'underfit' and obese children, creating an encouraging environment for participation in physical activity and sports at school and other settings, which is accompanied by psychological and social support.

Although a common protocol was used to evaluate anthropometric and fitness tests all over Greece, a very large number of professionals participated as evaluators in this study over the 11 years. Furthermore, potential confounding factors such as physical activity, maturation status, and nutrition habits were not evaluated. The selection of appropriate cut-off points for the fitness tests is another potential limitation. Although our choice for the quartile ranks in fitness tests is arbitrary, the National Children and Youth Fitness Study II suggested that for 6- to 9-year-old children test scores above the 25 th percentile (the poor quartile) should be considered acceptable from a health perspective [40]. Moreover, because of the large sample, statistical significance can easily be achieved for both sexes. Finally, the cross-sectional design of our study cannot provide causal relationships, but only hypotheses for further research.

In conclusion, the present study revealed that, simultaneously to an increase in obesity rates, aerobic fitness levels decreased over the last 11 years in Greek children. Moreover, we observed a rapid increase of poor quartile performances among 8- to 9-year-old children of both genders. Overweight/ obese children presented a higher risk of low performance compared with their normal-weight counterparts in almost all fitness tests. Urgent actions need to be taken from public health policy makers while parents and teachers should encourage physical activity and promote healthy food habits of the children.

\section{Acknowledgements}

This work was supported by the Hellenic Ministry of Culture, Secretariat General of Sports, the Hellenic Atherosclerosis Society and the Hellenic Heart Foundation. We are very grateful to Mr Dimitrios Economou (network administrator for the Secretariat General of Sports) for his assistance with data retrieval.

\section{Disclosure}

The authors declared no conflict of interest.

\section{References}

1 Kosti RI, Panagiotakos DB: The epidemic of obesity in children and adolescents in the world. Cen Eur J Public Health 2006;14:151-159.

$\checkmark 2$ Tambalis KD, Panagiotakos DB, Kavouras SA Kallistratos AA, Moraiti IP, Douvis SJ, Toutouzas PK, Sidossis LS: Eleven-year prevalence trends of obesity in Greek children: first evidence that prevalence of obesity is leveling off. Obesity (Silver Spring) 2010;18:161-166.

3 Weiss R, Dziura J, Burgert TS, Tamborlane WV, Taksali SE, Yeckel CW, Allen K, Lopes M, Savoye M, Morrison J, Sherwin RS, Caprio S. et al: Obesity and the metabolic syndrome in children and adolescents. N Engl J Med 2004;350:2362-74.

4 French SA, Story M, Jeffery RW: Environmental influences on eating and physical activity. Annu Rev Public Health 2001;22:309-335.

5 Ortega FB, Ruiz JR, Castillo MJ, Sjostrom M: Physical fitness in childhood and adolescence: a powerful marker of health. Int J Obes (Lond) 2008 32:1-11.

6 Andersen LB, Wedderkopp N, Hansen HS, Cooper AR, Froberg K: Biological cardiovascular risk factors cluster in Danish children and adolescents: the European Youth Heart Study. Prev Med 2003;37:363-367.

7 Gutin B, Islam S, Manos T, Cucuzzo N, Smith C, Stachura ME: Relation of percentage of body fat and maximal aerobic capacity to risk factors for atherosclerosis and diabetes in black and white seven- to eleven-year-old children. J Pediatr 1994; 125:847-852.
8 Gutin B, Yin Z, Humphries MC, Hoffman WH, Gower B, Barbeau P: Relations of fatness and fitness to fasting insulin in black and white adolescents. J Pediatr 2004;145:737-743.

9 Hurtig-Wennlof A, Ruiz JR, Harro M, Sjostrom M: Cardiorespiratory fitness relates more strongly than physical activity to cardiovascular disease risk factors in healthy children and adolescents: the European Youth Heart Study. Eur J Cardiovasc Prev Rehabil 2007;14:575-581.

10 Kasa-Vubu JZ, Lee CC, Rosenthal A, Singer K, Halter JB: Cardiovascular fitness and exercise as determinants of insulin resistance in postpubertal adolescent females. J Clin Endocrinol Metab 2005; 90:849-854.

11 Ekelund U, Anderssen SA, Froberg K, Sardinha LB, Andersen LB, Brage S: Independent associations of physical activity and cardiorespiratory fitness with metabolic risk factors in children: the European Youth Heart Study. Diabetologia 2007; 50:1832-1840.

12 Anderssen SA, Cooper AR, Riddoch C, Sardinha LB, Harro M, Brage S, Andersen LB: Low cardiorespiratory fitness is a strong predictor for clustering of cardiovascular disease risk factors in children independent of country, age and sex. Eur J Cardiovasc Prev Rehabil 2007;14:526-531.

13 Nassis GP, Psarra G, Sidossis LS: Central and total adiposity are lower in overweight and obese children with high cardiorespiratory fitness. Eur J Clin Nutr 2005;59:137-141.
14 Eisenmann JC, Wickel EE, Welk GJ, Blair SN: Relationship between adolescent fitness and fatness and cardiovascular disease risk factors in adulthood: the Aerobics Center Longitudinal Study (ACLS). Am Heart J 2005;149:46-53.

15 Williams PT: Physical fitness and activity as separate heart disease risk factors: a meta-analysis. Med Sci Sports Exerc 2001;33:754-761.

16 Olds T, Tomkinson G, Leger L, Cazorla G: Worldwide variation in the performance of children and adolescents: an analysis of 109 studies of the 20-m shuttle run test in 37 countries. J Sports Sci 2006;24: 1025-1038.

17 Stigman S, Rintala P, Kukkonen-Harjula K, Kujala U, Rinne M, Fogelholm M: Eight-year-old children with high cardiorespiratory fitness have lower overall and abdominal fatness. Int J Pediatr Obes 2009;4:98-105.

18 Stratton G, Canoy D, Boddy LM, Taylor SR, Hackett AF, Buchan IE: Cardiorespiratory fitness and body mass index of 9-11-year-old English children: a serial cross-sectional study from 1998 to 2004. Int J Obes (Lond) 2007:31:1172-1178.

19 Koutedakis Y, Bouziotas C, Flouris AD, Nelson $\mathrm{PN}$ : Longitudinal modeling of adiposity in periadolescent Greek schoolchildren. Med Sci Sports Exerc 2005;37:2070-2074.

20 Mamalakis G, Kafatos A, Manios Y, Anagnostopoulou T, Apostolaki I: Obesity indices in a cohort of primary school children in Crete: a six year prospective study. Int $\mathrm{J}$ Obes Relat Metab Disord 2000;24:765-771. 
21 Tokmakidis SP, Kasambalis A, Christodoulos AD: Fitness levels of Greek primary schoolchildren in relationship to overweight and obesity. Eur J Pediatr 2006;165:867-874.

22 Leger L, Lambert J, Goulet A, Rowan C, Dinelle Y: Aerobic capacity of 6 to 17-year-old Quebecois - 20 meter shuttle run test with 1 minute stages (Article in French). Can J Appl Sport Sci 1984;9: 64-69.

23 Leger LA, Mercier D, Gadoury C, Lambert J: The multistage 20 metre shuttle run test for aerobic fitness. J Sports Sci 1988;6:93-101.

24 Liu NYS, Plowman SA, Looney MA: The reliability and validity of the 20-meter shuttle test in American students 12 to 15 years old. Res Q Exerc Sport 1992;63:360-365.

25 van Mechlen W, Hlobil H, Kemper HCG: Validation of two running tests as estimates of maximal aerobic power in children. Eur J Appl Physiol 1986;55:503-506.

26 Cole TJ, Flegal KM, Nicholls D, Jackson AA: Body mass index cut offs to define thinness in children and adolescents: international survey. BMJ 2007;335:194.

27 Cole TJ, Bellizzi MC, Flegal KM, Dietz WH: Establishing a standard definition for child overweight and obesity worldwide: international survey. BMJ 2000;320:1240-1243.

28 Tomkinson GR, Olds TS: Secular changes in pediatric aerobic fitness test performance: the global picture. Med Sport Sci 2007;50:46-66.
29 Wei M, Kampert JB, Barlow CE, Nichaman MZ, Gibbons LW, Paffenbarger RS Jr, Blair SN: Relationship between low cardiorespiratory fitness and mortality in normal-weight, overweight, and obese men. JAMA 1999;282:1547-1553.

30 Froberg K, Andersen LB: Mini review: physical activity and fitness and its relations to cardiovascular disease risk factors in children. Int J Obes (Lond) 2005;29(suppl 2):S34-39.

31 Westerstahl M, Barnekow-Bergkvist M, Hedberg G, Jansson E: Secular trends in body dimensions and physical fitness among adolescents in Sweden from 1974 to 1995. Scand J Med Sci Sports 2003; 13:128-137.

32 Huotari PR, Nupponen H, Laakso L, Kujala UM: Secular trends in aerobic fitness and its determinants in Finnish 13- to 18-year-old adolescents from 1976 and 2001. Br J Sports Med 2010; 44:968-972.

33 Perusse L, Rankinen T, Rauramaa R, Rivera MA, Wolfarth B, Bouchard C: The human gene map for performance and health-related fitness phenotypes: the 2002 update. Med Sci Sports Exerc 2003; 35:1248-1264.

34 Tomkinson GR, Olds TS: Secular changes in pediatric aerobic fitness test performance: the global picture. Med Sport Sci 2007;50:46-66

35 Tomkinson GR: Global changes in anaerobic fitness test performance of children and adolescents (1958-2003). Scand J Med Sci Sports 2007;17:497507.
36 Bovet P, Auguste R, Burdette H: Strong inverse association between physical fitness and overweight in adolescents: a large school-based survey. Int J Behav Nutr Phys Act 2007;4:24.

37 Chen W, Lin CC, Peng CT, Li CI, Wu HC, Chiang J, Wu JY, Huang PC: Approaching healthy body mass index norms for children and adolescents from health-related physical fitness. Obes Rev 2002;3:225-232.

38 Kim J, Must A, Fitzmaurice GM, Gillman MW, Chomitz V, Kramer E, McGowan R, Peterson KE: Relationship of physical fitness to prevalence and incidence of overweight among schoolchildren. Obes Res 2005;13:1246-1254.

39 Nassis GP, Papantakou K, Skenderi K, Triandafillopoulou M, Kavouras SA, Yannakoulia M, Chrousos GP, Sidossis LS: Aerobic exercise training improves insulin sensitivity without changes in body weight, body fat, adiponectin, and inflammatory markers in overweight and obese girls. Metabolism 2005;54:1472-1479.

40 Ross JG, Pate RR, Delpy LA, Gold RS, Svilar M: The national children and youth study fitness study II. New health-related fitness norms. JOPERD 1987;58:66-70. 